\title{
Reactive oxygen intermediates in autoimmune islet cell destruction of the NOD mouse induced by peritoneal exudate cells (rich in macrophages) but not $T$ cells
}

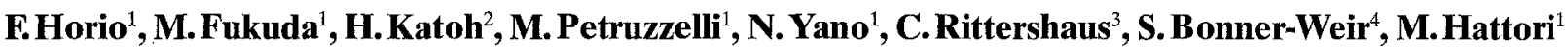 \\ ${ }^{1}$ Section on Immunology and Immunogenetics, Joslin Diabetes Center, Department of Medicine, Brigham and Women's Hospital, \\ Harvard Medical School, Boston, Massachusetts, USA \\ ${ }^{2}$ Central Institute for Experimental Animals, Kawasaki, Japan \\ ${ }^{3}$ T-Cell Sciences, Cambridge, Massachusetts, USA \\ ${ }^{4}$ Section on Islet Cell Physiology and Transplantation, Joslin Diabetes Center, Department of Medicine, \\ Brigham and Women's Hospital, Harvard Medical School, Boston, Massachusetts, USA
}

\begin{abstract}
Summary The non-obese diabetic (NOD) mouse spontaneously develops autoimmune Type 1 (insulindependent) diabetes mellitus. NOD mice exhibit massive infiltrates of $T$ cells and macrophages into pancreatic islets (insulitis) prior to diabetes. The contribution of oxygen free radicals to the development of insulitis in NOD mice was examined by administration of its scavengers, such as superoxide dismutase and catalase. Bovine superoxide dismutase and catalase were each coupled to polyethylene glycol. The treatment with superoxide dismutase-polyethylene glycol reduced the number of islets with insulitis and increased the undamaged islet tissue, as compared with the control group. The treatment with catalase-polyethylene glycol showed a similar tendency which did not reach significance. Using a flow cytometric assay of the oxidation of $2^{\prime}, 7^{\prime}$-dichlorofluorescein, the content of reactive oxygen intermediates in islet cells in the culture
\end{abstract}

system was measured and the effect of peritoneal exudate cells and $T$ cells on their production examined. Peritoneal exudate cells, but not T cells, from NOD mice increased the content of reactive oxygen intermediates in islet cells of either the NOD mouse or the ILI mouse (MHC-identical to NOD); the addition of superoxide dismutase to the culture medium suppressed this increase in NOD or ILI islet cells. The present data support the concept that production of oxygen free radicals mediated by macrophages can damage islet beta cells, directly resulting in autoimmune Type 1 diabetes in NOD mice. [Diabetologia (1994) 37:22-31]

Key words NOD mice, insulitis, reactive oxygen intermediates, superoxide dismutase, peritoneal macrophages.
Lymphoid cell infiltration into pancreatic islets (insulitis) is a well-recognized feature of Type 1 (insulindependent) diabetes mellitus both in humans [1] and in rodents with spontaneous diabetes $[2,3]$. The nonobese diabetic (NOD) mouse spontaneously develops an insulin-dependent diabetes. NOD mice exhibit massive infiltrates of lymphoid cells and macrophages into pancreatic islets (insulitis) prior to complete betacell destruction, and insulitis appears as early as 5 weeks of age. Makino and co-workers [4] have shown

Received: 26 April 1993

and in revised form: 15 July 1993

Corresponding author: Dr. M. Hattori, Section on Immunology and Immunogenetics, Joslin Diabetes Center, Harvard Medical School, One Joslin Place, Boston, MA 02215, USA that $\mathrm{T}$ cells play an important role in the development of insulitis and diabetes in nude NOD mice. The major infiltrating cell populations in the insulitis lesion are $\mathrm{CD}^{+}{ }^{+}$(L3T4, helper) and CD8 ${ }^{+}$(Ly2, cytotoxic/suppressor) $\mathrm{T}$ cells, and macrophages [5]. Splenocytes from diabetic NOD mice can transfer diabetes to irradiated non-diabetic young NOD mice [6]. Both $\mathrm{CD}^{+}$and $\mathrm{CD}^{+}{ }^{+}$splenic $\mathrm{T}$ cells are required to transfer diabetes from diabetic NOD mice to irradiated nondiabetic NOD mice. In T-cell mediated immune processes, the immune responses to self-antigens are dependent on certain combinations of $\mathrm{MHC}$ and the Tcell receptor (TcR) V $\beta$ family. Restricted TcR usage has been found in some T-cell dependent autoimmune disease, for example TcR V $\beta 8$ is preferentially used in experimental autoimmune encephalomyelitis [7]. Restriction of TcR usage in autoimmune diabetes has not 
been confirmed in the NOD mouse $[8,9]$. However, T cells bearing TcR V $\beta 8$ are the major population in the islet-infiltrating cells of diabetic NOD mice [5]. The precise mechanisms by which lymphocytes and macrophages damage islet beta cells remain unclear.

In chemically-induced diabetes, several mechanisms of islet beta-cell damage have been proposed. Streptozotocin and alloxan break nuclear DNA strands of islet beta cells by generating oxygen free radicals $[10,11]$. Streptozotocin and its nitrosoamide moiety methylnitrourea alkylate the DNA of beta cells and cause comparable amounts of DNA strand breakage $[12,13]$. Streptozotocin alkylates not only DNA but also other key cellular components [14]. Poly (ADPribose) synthetase inhibitors such as nicotinamide and 3-aminobenzamide can scavenge oxygen free radicals in pancreatic beta cells produced by streptozotocin and alloxan in monolayer culture system [15]. Since nicotinamide and 3 -aminobenzamide were also reported to prevent the development of spontaneous diabetes in the NOD mouse [16], the same mechanism may be involved in islet beta-cell destruction of the NOD mouse as that in streptozotocin- and alloxan-induced diabetes. Macrophages [17] and probably T cells produce oxygen free radicals in inflammatory reactions. It is reasonable to hypothesize that oxygen free radicals produced by macrophages and $T$ cells in the insulitis lesion may destroy islet beta cells leading to the development of diabetes in NOD mice $[18,19]$ and that oxygen free radical scavengers, such as superoxide dismutase (SOD) and catalase, may prevent the destruction of beta cells and ensuing diabetes. In this study, we have examined the effects of SOD and catalase on the development of insulitis, and splenic T-cell populations in NOD mice. In addition, the production of reactive oxygen intermediates in pancreaticislet cells induced by peritoneal exudate cells (rich in macrophages) and $\mathrm{T}$ cells from celiac lymph nodes of the NOD mouse in vitro was investigated.

\section{Materials and methods}

\section{Animals}

Non-obese diabetic (NOD) mice were originally obtained from the colony of Dr. S. Makino at the Aburahi Laboratories, Shionogi and Company, Ltd., (Shiga, Japan). NOD/Shi//Jos females develop diabetes at $92 \%$ incidence and NOD males at less than $60 \%$ incidence by 30 weeks of age. The Institute of Cancer Research-L-Ishibe (ILI) mouse, which is a sister strain of the NOD mouse and is MHC-identical to the NOD mouse, does not develop insulitis or diabetes [20]. Male and female NOD/Shi//Jos and ILI/Jic//Jos mice at 5 months of age were used as a source of pancreatic islet cells in this study. Diabetic NOD mice within 2 weeks after the onset of diabetes were used as a source of peritoneal exudate cells. For the assay of oxygen free radical production in islet cells by NOD peritoneal exudate cells, sex-matched animals were used. The NOD mice were given ad libitum commercial chow (Agway Prolab 3000 Formula; Agway, Syracuse, NY, USA), and water.
Treatment with superoxide dismutase-polyethylene glycol and catalase-polyethylene glycol

Fifteen NOD female litter mates from three litters were divided into three groups at 10 weeks of age. Five female NOD mice in each group were injected (intraperitoneally, daily for 14 days) with either superoxide dismutase-polyethylene glycol (SODPEG, $225 \mathrm{U}$ per day per mouse, $55 \mu \mathrm{g}$ protein, source: bovine erythrocytes; Sigma, St. Louis, Mo, USA), catalase-PEG (2,310 U per day per mouse, $57 \mu$ g protein , source: bovine liver; Sigma), or the vehicle alone (PEG, $45 \mu \mathrm{g}$ per day per mouse; Sigma). SOD-PEG, catalase-PEG and PEG were dissolved in phosphate-buffered saline (PBS; $137 \mathrm{mmol} \mathrm{NaCl}, 15 \mathrm{mmol}$ $\mathrm{Na}_{2} \mathrm{HPO}_{4}, 1.47 \mathrm{mmol} \mathrm{KH}_{2} \mathrm{PO}_{4}, 2.68 \mathrm{mmol} \mathrm{KCL}$ ), pH 7.3. For $\mathrm{PEG}$ alone $45 \mu \mathrm{g}$ was an equivalent dose compared to the compound of SOD-PEG $(225 \mathrm{U})$. The animals were killed at 12 weeks of age after collecting blood samples under ether anaesthesia. The pancreas and spleen were removed and subjected to histological and immunological examinations, respectively.

\section{Assay of the activities of SOD and catalase in plasma}

Blood samples $(0.4 \sim 0.5 \mathrm{ml})$ were collected with a heparinized pasteur pipette from the retro-orbital venous plexus of the animals under ether anaesthesia. Each animal was assayed for SOD and catalase before and after the treatment. The activity of SOD in heparinized plasma was measured according to the method of McCord and Fridovich [21]. Plasma was diluted ten-fold with $0.9 \% \mathrm{NaCl}$ (in catalase-PEG and control group) or 100-fold (SOD-PEG group) and used for the SOD assay. The activity of catalase in plasma was assayed according to the method of Beers and Sizer [22]. One unit of catalase decomposed $1.0 \mu \mathrm{mol}$ hydrogen peroxide per min at $25^{\circ} \mathrm{C}$.

\section{Point-counting morphometrics of the islets}

The animals were killed under ether anaesthesia, and pancreases removed and weighed. For morphometric analysis it has been shown that there is usually more biological variation between animals than between sections if the tissue is either homogenous or consistently oriented in the same plane. The pancreases were oriented in the same plane and spread prior to fixation in Bouin's solution. With these procedures, a large cross-sectional area of pancreas was obtained and only one "level" or section per animal was required to have adequate number of intercepts (5000 points per animal). The tissues were embedded in paraffin, cut at $6 \mu \mathrm{m}$ and stained with haematoxylin and eosin. Using one section per animal, all islets on each section were scored for insulitis; the number of islets per section ranged from 17 to 41 . Two separate quantifications were performed to evaluate the protective effect of SOD and catalase on islet cell destruction. First, the number of islets with insulitis and the total number of islets were counted at $100 \times$ magnification. The ratio of these values multiplied by 100 gave the percent islets with insulitis. Secondly, the islet portion without infiltrating immune cells was defined as the undamaged islet portion. The relative volume of undamaged islet portion was measured by pointcounting morphometrics [23] at $170 \times$ magnification, covering the entire section with non-overlapping fields of a 50-point grid. The number of points counted per animal was approximately 5,000. The absolute mass of undamaged islet portion was then calculated by multiplying the relative volume by the pancreatic weight for each animal. 


\section{Antibodies}

Monoclonal antibodies (mAb) used to characterize splenic lymphoid cells and peritoneal exudate cells were fluorescein isothionate (FITC)-conjugated or biotinylated $\mathrm{mAb}$ anti-mouse Thy1.2 (Becton Dickinson, Mountain View, Calif., USA) for $\mathrm{T}$ cells, phycoerythrin (PE)-conjugated mAb GK1.5 anti-L3T4 (Becton Dickinson) for CD4 T cells, FITC-conjugated mAb 53-6 anti-mouse Ly2 (Becton Dickinson) for CD8 T cells, FITC-conjugated goat anti-mouse IgM (Organon Teknika, Malvern, Pa., USA) for B cells, mAb M3/84.6.34 (rat IgG1, American Type Culture Collection, Rockville, Md., USA) and mAb M1/70.15 (rat IgG2b, Caltag Laboratories, South San Francisco, Calif., USA) for macrophages, mAb PK 136 anti-mouse natural killer cells (IgG2a) and rabbit anti-asialo GM1 (Wako Fine Chemical, Dallas, Tx., USA) for natural killer cells. Antisera used as controls were: monoclonal antibody P3X63 for mAb anti-mouse Thy1.2, normal mouse serum for anti-mouse IgM, mAb antiL3T4 and Ly2, normal rat IgG for $\mathrm{mAb} \mathrm{M} 3 / 84.6 .34$ and $\mathrm{mAb}$ M1/70.15, and normal rabbit serum for rabbit anti-asialo GM1.

Monoclonal antibodies used in studying TcR $\alpha \beta$, TcR V $\beta 8$ and CD3 $(\varepsilon)$ were $\mathrm{mAb}$ H57-597 (hamster IgG) pan anti-mouse $\mathrm{TcR} \alpha \beta$ [24], mAb F23.1 (mouse IgG 2a) anti TcR V $\beta 8.1,2,3$ [25], and $\mathrm{mAb} 145-2 \mathrm{C} 11$ hamster anti-mouse CD3 $(\varepsilon)$ [26], respectively. Antisera used as controls were: normal hamster serum for $\mathrm{mAb}$ 57-597.2 and 145-2C11, and purified mouse myeloma RPC 5.4 (IgG 2a, Organon Teknika) for mAb F23.1.

\section{Splenic T cells}

Spleens were dissected from the 12-week-old NOD mice after the 2-week administration of SOD-PEG, catalase-PEG and $\mathrm{PEG}$, and dissociated by gentle passage through a wire screen. Lymphoid cells were separated from erythrocytes with Ficoll400 (Lympholyte-M; Cederlane, Province, Canada), and washed twice with RPMI-1640 medium containing $5 \%$ fetal calf serum (FCS). B cells were stained directly with FITC-conjugated goat anti-mouse IgM. The lymphoid cell suspensions were applied to a nylon wool column (Wako Fine Chemical), and incubated at $37^{\circ} \mathrm{C}$ for $45 \mathrm{~min}$. T cells were then eluted with pre-warmed RPMI-1640 medium containing $5 \%$ FCS. T cells were stained with FITC-conjugated $\mathrm{mAb}$ anti-mouse Thy 1.2 before and after the purification on nylon wool column to determine the recovery and the purity of T cells (95\%).

The purified T cells were incubated with FITC-conjugated $\mathrm{mAb}$ anti-mouse Ly2 or phycoerythrin-conjugated $\mathrm{mAb}$ antimouse L3T4 on ice for $45 \mathrm{~min}$, washed three times with medium RPMI-1640. Furthermore, the purified T cells were incubated with $\mathrm{mAb} 145-2 \mathrm{C} 11$ (TcR $\alpha \beta$ ), mAbH57-597 (TcR V $\beta$ 8) or heatinactivated normal hamster serum on ice for $45 \mathrm{~min}$. T cells were incubated with $\mathrm{AAb}$ F23.1 or mouse myeloma protein RPC 5.4 at $37^{\circ} \mathrm{C}$ for $30 \mathrm{~min}$. After the incubation, $\mathrm{T}$ cells were washed three times with RPMI-1640 medium, and then stained with FITC-conjugated goat anti-hamster IgG or goat anti-mouse IgG (Fc specific). The cells were fixed in $2 \%$ formaldehyde-PBS, and stored at $4{ }^{\circ} \mathrm{C}$ until flow cytometric analysis. The percentage of fluorescein-positive cells were measured by flow cytometer. The absolute number of B cells and T cells in each subset was estimated from the total number of cells and the percentage of positive cells.

\section{Islet cell preparations}

Islets were isolated from non-diabetic 16-week-old NOD or ILI males. NOD males were chosen because of the lesser degree of islet damage than in NOD females. Islets were also isolated from
ILI males. ILI mice were chosen because this strain is MHCidentical to the NOD mouse and develops neither insulitis nor diabetes. The animals were anaesthetized intraperitoneally with pentobarbital (Na Salt; 0.5-1.0 mg/mouse; Sigma). Collagenase Type IV (Organon Teknika) solution ( $4 \mathrm{ml}$ of $2 \mathrm{mg} / \mathrm{ml}$ in Hank's balanced salt solution) was infused into the pancreatic duct after ligating the common bile duct at its entrance to the duodenum. The expanded pancreas was digested at $38^{\circ} \mathrm{C}$ for $30 \mathrm{~min}$ and islets were purified on Ficoll gradients $(25,23,20.5$ and $11 \%)$ and centrifuged at room temperature $(\times 800 \mathrm{~g}, 10 \mathrm{~min})$. The islets were hand picked to avoid contamination by exocrine cells and connective tissues. To prepare single islet cells, isolated islets were washed with $\mathrm{Ca}$ - or $\mathrm{Mg}$-free PBS and digested with trypsin solution for $2 \mathrm{~min}$. After complete dissociation, the islet cells were washed twice with medium RPMI-1640 containing $5 \%$ FCS.

\section{Peritoneal exudate cells}

Peritoneal exudate cells were collected from non-diabetic 16week-old NOD males in Experiment 1 and diabetic NOD females in Experiment 2 by lavage of the peritoneal cavity with RPMI-1640 medium containing $2 \%$ FCS. The peritoneal exudate cells consisted of macrophages $(60 \%)$, T cells $(7 \%), \mathrm{B}$ cells $(6 \%)$ and anti-asialo $\mathrm{GM1}^{+}$cells $(27 \%)$ in non-diabetic NOD males and diabetic NOD females shortly after the onset of diabetes. Peritoneal T cells (PTc) were prepared by passing the peritoneal exudate cells through nylon wool columns (T-cell purity: 97\%). The macrophage-enriched fraction (peritoneal macrophages, $\mathrm{PM} \varnothing$ ) was recovered from the nylon wool (PM $\varnothing$ purity: $75 \%$ ) and contained a very small number of $T$ cells (less than $3 \%$ ).

\section{Celiac lymph node T cells}

Lymphoid cells from the pancreas are mainly drained into the celiac lymph nodes and through the efferent lymphatic vessels leading to the cisterna chyli. Diabetic and non-diabetic NOD mice but not C57BL/6J, BALB/cJ and NON/Jos mice showed enlargement of the celiac lymph nodes with an increased number of $\mathrm{T}$ cells (unpublished observation). Injection of lymphocytes $\left(2 \times 10^{7}\right)$ from the enlarged celiac lymph nodes from diabetic NOD mice transferred diabetes into irradiated young NOD mice. As a source of T cells, celiac lymph nodes were dissected from non-diabetic 16-week-old NOD males or diabetic NOD females, and dissociated to yield single-cell suspensions. The cell suspensions contained T cells (70\%), B cells (26\%) and macrophages $(6 \%)$ and $T$ cells were purified by passing through a nylon wool column.

\section{Measurement of reactive oxygen intermediates (hydrogen peroxide) in islet cells}

Four experiments were designed to investigate the production of reactive oxygen intermediates in islet cells. Experiment 1 was designed to test the production of reactive oxygen intermediates in islet cells from male NOD or ILI mice with peritoneal exudate cells and $T$ cells from non-diabetic NOD males. Islet cells isolated from either NOD males (culture A-E) or ILI males (culture $\mathrm{F}-\mathrm{J}$ ) were used for the measurement of reactive oxygen intermediates. Peritoneal exudate cells were prepared from the non-diabetic NOD male mice. Isolated islet cells $\left(2 \times 10^{5}\right.$ cells $)$, celiac T cells (nylon wool purified T cells, $4 \times 10^{5}$ cells), and peritoneal exudate cells $\left(4 \times 10^{5}\right.$ cells $)$ were cultured overnight in the 
A

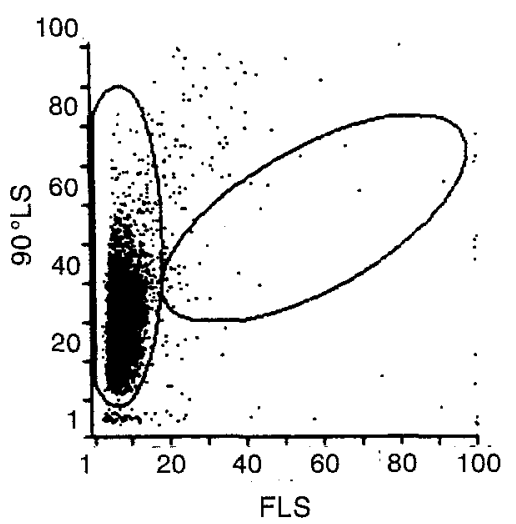

B

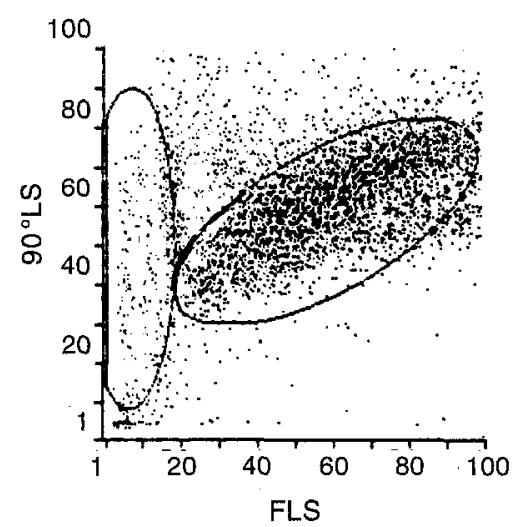

c

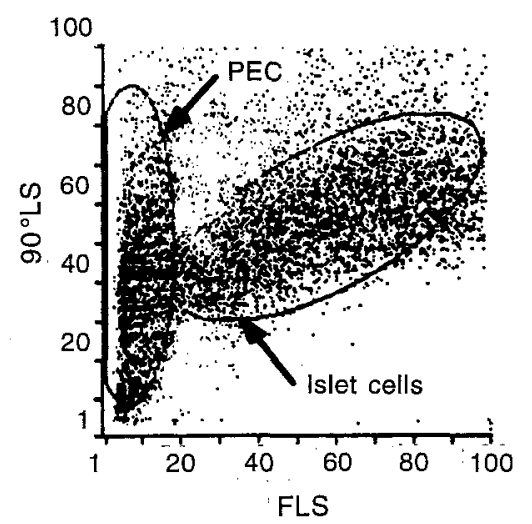

Fig. 1 A-C. Cytograms of bit map gating for distinguishing (A) peritoneal exudate cells (PEC), (B) islet cells and (C) both PEC + islet cells from NOD mice. Five thousand PEC and 5000 islet cells were examined by light scatter characteristic. FLS, forward light scatter; $90^{\circ} \mathrm{LS}, 90^{\circ}$ light scatter

medium RPMI-1640 (total volume, $200 \mu \mathrm{l}$ ) containing $5 \% \mathrm{FCS}$, $15 \%$ concanavalin-A-stimulated NOD splenocyte conditioned media, and $1 \%$ fresh L-glutamine in a humidified atmosphere $\left(5 \% \mathrm{CO}_{2}\right.$ and $95 \%$ air, at $\left.37^{\circ} \mathrm{C}\right)$. Several combinations of islet cells, $\mathrm{T}$ cells and peritoneal exudate cells were tested in the culture system. After overnight culture, the content of reactive oxygen intermediates (hydrogen peroxide) in islet cells was measured using the flow cytometric method of Bass and co-workers [27]. The 2', 7'-dichlorofluorescein diacetate (DCFH-DA; Eastman Kodak, Rochester, NY, USA) was added to the medium (final concentration, $50 \mu \mathrm{mol} / \mathrm{l}$ ), and cells were then cultured for $20 \mathrm{~min}$ at $37^{\circ} \mathrm{C}$. DCFH incorporated into islet cells was oxidized rapidly to fluorescent form by intracellular hydrogen peroxide. SOD was added to culture $\mathrm{E}$ or J (final concentration, $13.4 \mathrm{U} / \mathrm{ml}$ ) in combination with DCFH-DA. Then, the fluorescence of islet cells was determined on a flow cytometer (Cytofluorograph 50H; Ortho Diagnostic System Inc., Westwood, Mass., USA). Islet cells were separated from the co-culturing peritoneal exudate cells (PEC) by electric gating on a forward light scatter vs $90^{\circ}$ bit map (Fig. 1).

Experiment 2 was designed to test the production of reactive oxygen intermediates in islet cells from female ILI mice with peritoneal exudate cells and T cells from diabetic female NOD mice. Islets were isolated from non-diabetic 16-week-old ILI females. Peritoneal exudate cells and celiac lymph node cells were prepared from diabetic NOD females within 2 weeks after the onset of diabetes. The ILI islet cells were cultured with peritoneal exudate cells, peritoneal macrophages, peritoneal $T$ cells or $T$ cells of the celiaclymph nodes from the diabetic NOD females. The culture conditions were the same as in Experiment 1 except that the culture time of the islet cells with peritoneal exudate cells was reduced from overnight to $3 \mathrm{~h}$. Reactive oxygen intermediate production in the islet cells was measured in the same manner as in Experiment 1.

Experiment 3 was designed to test direct oxidation of $2^{\prime}, 7^{\prime}$ dichlorofluorescein (DCFH) in islet cells by hydrogen peroxide $\left(\mathrm{H}_{2} \mathrm{O}_{2}\right)$. Islet cells $\left(2 \times 10^{5}\right)$ from $\mathrm{C} 3 \mathrm{H} / \mathrm{HeJ}$ mice (MHC-haplotype: $\mathrm{k}$ ) were incubated with $2^{\prime}, 7^{\prime}$-dichlorofluorescein diacetate (final concentration, $50 \mu \mathrm{mol} / \mathrm{l}$ ) for $30 \mathrm{~min}$ and followed by incubation with hydrogen peroxide (10 to $100 \mu \mathrm{mol} / \mathrm{l}$; Sigma) for $15 \mathrm{~min}$. The fluorescence of islet cells was then determined on a flow cytometer. The specificity of peritoneal exudate cells from NOD, ILI and C3H/He mice was also examined.

Experiment 4 was designed to test the production of reactive oxygen intermediates in islet cells by cytokines produced by macrophages. Islet cells $\left(2 \times 10^{5}\right)$ from ILI mice were incubated with recombinant mouse interleukin-1- $\alpha$ (40 U; Genzyme Boston, Mass., USA) for $3 \mathrm{~h}$ and followed by incubation with DCFH-DA for $20 \mathrm{~min}$ and flow cytometric analysis.

\section{Statistical analysis}

Statistical analysis was performed by the Mann-Whitney $\mathrm{U}$ test.

\section{Results}

\section{Treatment with SOD-PEG or catalase-PEG}

The 2-week treatment with SOD-PEG or catalasePEG did not affect the growth nor cause signs of visible allergic reactions such as skin rash and anaphylaxis in the animals. The plasma activity of SOD in the SODPEG group increased more than 100-fold compared with that in the control group (Table 1). The plasma activity of catalase in the catalase-PEG group increased four-fold compared to that in the control group.

The pancreases from the above three groups were subjected to morphometric analysis. The number of islets examined on each section is listed in Table 2. There were no significant changes in the pancreatic weight among the SOD-PEG, catalase-PEG and PEG groups $(213.9 \pm 8.0 \mathrm{mg}, 204.5 \pm 8.8 \mathrm{mg}$, and $196.2 \pm 14.2 \mathrm{mg}$, respectively). The percentage of islets with insulitis was reduced in the SOD-PEG group to $50 \%$ of the PEG group and in the catalase-PEG group to $60 \%$ of the PEG group (Table 2). With either SOD-PEG or catalase-PEG treatment, the absolute mass of undamaged islets was two times greater than that of the PEG group. Without administration of SOD-PEG, catalase-PEG or PEG, in 3-month-old female NOD mice $(n=6)$ the mean percentage of islets with insulitis was $51.2 \pm 9.1 \%$, the relative volume of undamaged islets $0.45 \pm 0.10 \%$, and the absolute mass of undamaged is- 
Table 1. The plasma activity of superoxide dismutase (SOD) and catalase in NOD mice before and after the 2-week administration of SOD-PEG and catalase-PEG

\begin{tabular}{|c|c|c|c|c|c|c|}
\hline & \multicolumn{2}{|c|}{ Body weight (g) } & & & & \\
\hline & \multirow{2}{*}{$\begin{array}{l}10 \text { weeks old } \\
\text { before }\end{array}$} & \multirow{2}{*}{$\begin{array}{l}12 \text { weeks old } \\
\text { after }\end{array}$} & \multicolumn{2}{|c|}{ SOD activity (U/ml) } & \multicolumn{2}{|c|}{ Catalase activity (U/ml) } \\
\hline & & & before & after & before & after \\
\hline Catalase-PEG & $22.2 \pm 0.2$ & $23.0 \pm 0.1$ & $3.0 \pm 0.4$ & $2.2 \pm 0.1$ & $17.8 \pm 1.0$ & $83.0 \pm 13.5^{\mathrm{a}}$ \\
\hline PEG alone & $21.5 \pm 0.7$ & $22.1 \pm 0.7$ & $3.6 \pm 0.3$ & $3.5 \pm 1.2$ & $15.0 \pm 2.5$ & $22.2 \pm 1.9$ \\
\hline
\end{tabular}

Values are expressed as mean $\pm \mathrm{SEM}, n=5$ mice in each group. ${ }^{a} p<0.05$, significant difference from the value of control (PEG

alone) in each experiment by Mann-Whitney U test. PEG, Polyethylene glycol

Table 2. Effects of superoxide dismutase-polyethylene glycol (SOD-PEG) and catalase-PEG on the degree of islet damage of the female NOD mouse at 3 months of age

\begin{tabular}{llcccc}
\hline Group & $\begin{array}{l}\text { No. of } \\
\text { animals }\end{array}$ & $\begin{array}{l}\text { No. of islets/section } \\
\text { observed }\end{array}$ & $\begin{array}{l}\text { \% of islets with } \\
\text { insulitis }\end{array}$ & $\begin{array}{l}\text { Relative volume of un- } \\
\text { damaged islet portion (\%) }\end{array}$ & $\begin{array}{l}\text { Absolute mass of un- } \\
\text { damaged islet portion (mg) }\end{array}$ \\
\hline SOD-PEG & 5 & $34 \pm 3$ & $18.7 \pm 4.8^{\mathrm{a}}$ & $0.91 \pm 0.04^{\mathrm{a}}$ & $1.93 \pm 0.04^{\mathrm{a}}$ \\
& & $(26-41)$ & $(6.9 \sim 30.8)$ & $(0.79 \sim 1.03)$ & $(1.83 \sim 2.06)$ \\
Catalase-PEG & 5 & $25 \pm 4$ & $25.7 \pm 10.5$ & $0.83 \pm 0.16$ & $1.68 \pm 0.30^{\mathrm{a}}$ \\
& & $(17-34)$ & $(4.0 \sim 54.2)$ & $(0.36 \sim 1.27)$ & $(0.76 \sim 2.60)$ \\
PEG alone & 5 & $24 \pm 4$ & $45.2 \pm 5.2$ & $0.45 \pm 0.05$ & $0.86 \pm 0.09$ \\
& & $(17-38)$ & $(31.6 \sim 57.1)$ & $(0.36 \sim 0.57)$ & $(0.66 \sim 1.14)$ \\
\hline
\end{tabular}

Values are expressed as mean $\pm S E M$, Number in parentheses is the range.

${ }^{a} p<0.05$, significant difference from the value of control (PEG alone) in each experiment by Mann-Whitney U test

Table 3. Quantitative analysis of B cells and T cells in the spleen of the NOD mouse after administration of superoxide dismutasepolyethylene glycol (SOD-PEG) and catalase-PEG

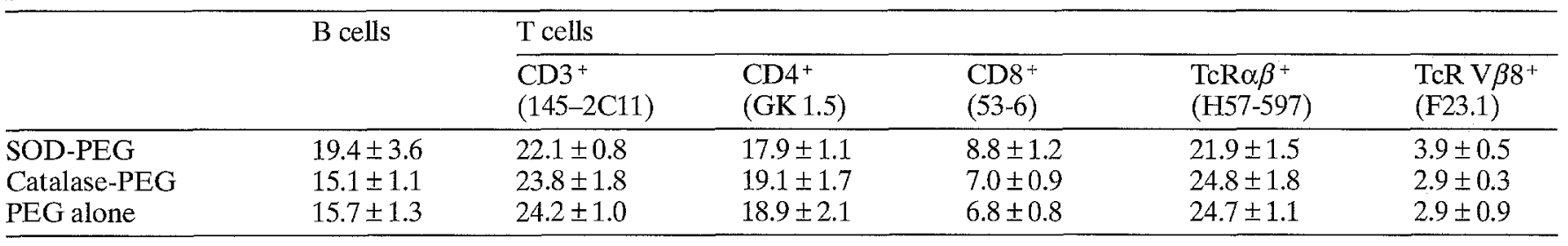

Values are expressed as mean $\pm \operatorname{SEM}\left(\times 10^{-6}\right.$ cells $), n=5$ mice in each group. For T cells, monoclonal antibodies in parentheses

lets $0.82 \pm 0.18 \mathrm{mg}$. The degree of islet damages in the untreated NOD females was similar to that in the PEGtreated NOD females at 3 months of age.

The number of splenic B cells and T-cell subsets was examined in the SOD-PEG, catalase-PEG and PEG animals (Table 3 ). There were no changes in the number of B cells, T cells, CD4 ${ }^{+} \mathrm{T}$ cells and $\mathrm{CD} 8^{+} \mathrm{T}$ cells after the treatment with SOD-PEG or catalase-PEG, nor in the T-cell subsets bearing TcR $\alpha \beta$ chains, and TcR $V \beta 8.1,2,3$, as compared with those of the PEG alone control group.

\section{Reactive oxygen intermediate production in islet cells}

Experiment 1: peritoneal exudate cells from nondiabetic NOD males. Histograms (expanded log scale$X$ axis) in Figure 2 show fluorescence distribution of DCFH oxidation in islet cells of the NOD mouse and the ILI mouse. Isolated islet cells of the NOD mouse did not produce reactive oxygen intermediates (Fig. 2A). The $T$ cells from celiac lymph nodes of the NOD mouse did not induce production of reactive oxygen intermediates in the NOD islet cells (Fig. 2B). Peritoneal exudate cells of the NOD mouse resulted in the production of reactive oxygen intermediates in the NOD islet cells (Fig. 2C). Combination of peritoneal exudate cells $\left(4 \times 10^{5}\right.$ cells $)$ and T cells $\left(4 \times 10^{5}\right.$ cells $)$ did not enhance and rather slightly suppressed the production of reactive oxygen intermediates in the NOD islet cells (Fig. 2D). Addition of SOD $(13.4 \mathrm{U} / \mathrm{ml})$ to peritoneal exudate cells $+T$ cells partially inhibited the production of reactive oxygen intermediates in the NOD islet cells (Fig. 2E). Nylon wool (and Sephadex G-10) purified T cells (purity: $>95 \%$ ) isolated from the NOD peritoneal exudate cells failed to induce the production of reactive oxygen intermediates in the islet cells. 
NOD islet cells

A

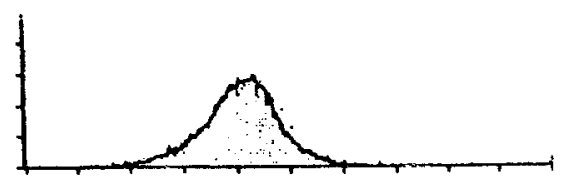

B

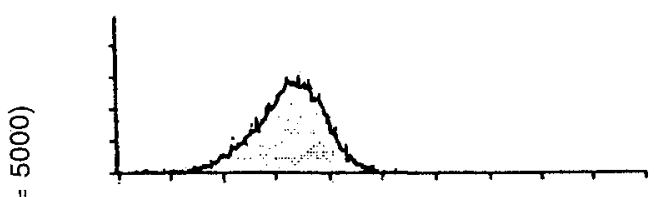

C

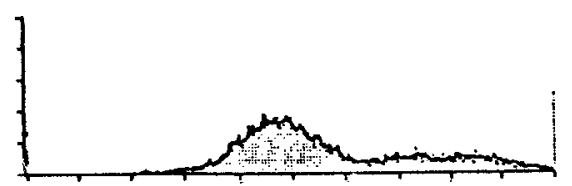

D

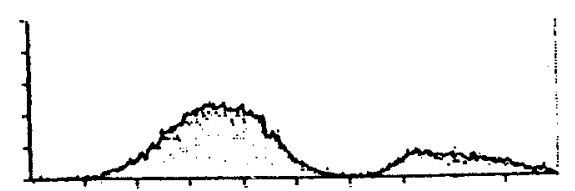

E

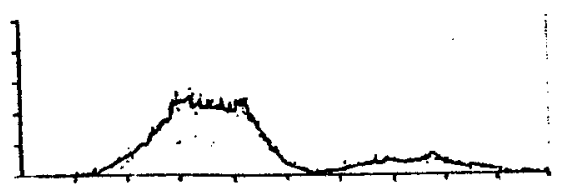

ILI islet cells

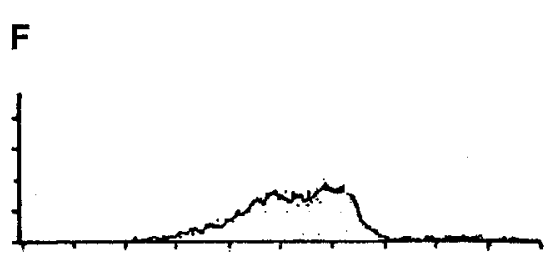

G

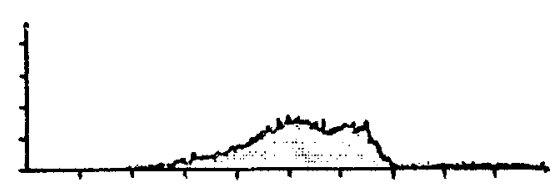

H

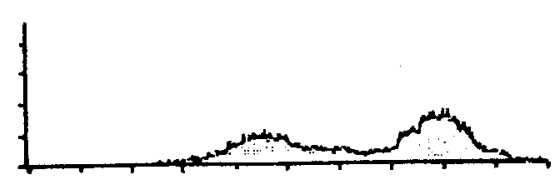

I

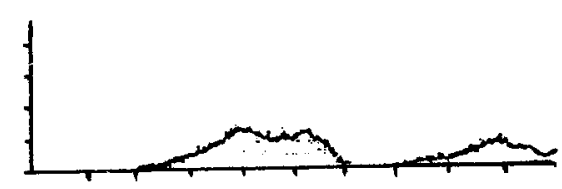

$\mathbf{J}$

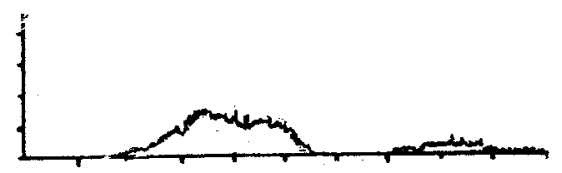

Fig. 2 A-J. Histograms of fluorescence distribution of $2^{\prime}, 7^{\prime}$ - $\mathrm{Di}$ chlorofluorescein (DCFH) oxidation in islet cells from NOD or ILI male mice induced by peritoneal exudate cells from non-diabetic NOD male mice. T cells of the celiac lymph nodes from nondiabetic male NOD mice were also tested to induce reactive oxygen intermediates in the islet cells. The islet cells and the effector cells were co-cultured overnight prior to the addition of DCFH-DA. Note the fluorescence intensity (on the $X$-axis) is expressed as "expanded log scale". Culture conditions were described in Materials and methods. The histograms represent numbers of cells (on the $Y$-axis) as a function of fluorescence intensity (on the $X$-axis). Percent of fluorescence-positive islet cells of the NOD mouse is shown in parentheses:

A: NOD islet cells alone (1.2\%);

B: NOD islet cells + T cells

$(0.4 \%)$;

C: NOD islet cells + peritoneal exudate cells ( $35.1 \%)$;

D: NOD islet cells + peritoneal exudate cells + T-cells $(28.0 \%)$; E: NOD islet cells + peritoneal exudate cells $+\mathrm{T}$ cells + superoxide dismutase $(19.1 \%)$;

F: ILI islet cells alone $(7.1 \%)$;

G: $I L I$ islet cells $+\mathrm{T}$ cells $(10.2 \%)$;

$\mathbf{H}$ : ILI islet cells + peritoneal exudate cells $(52.6 \%)$;

I: ILI islet cells + peritoneal exudate cells + T cells $(44.7 \%)$;

J: ILI islet cells + peritoneal exudate cells + T cells + superoxide dismutase, $(21.0 \%)$. The histograms represent one of five experiments
The ILI mouse is MHC-identical to the NOD mouse but does not develop insulitis or diabetes. Islet cells of the ILI mouse were tested for reactive oxygen intermediate production by peritoneal exudate cells of the NOD mouse. The results from the flow cytometric analysis of the ILI islet cells were similar to those of the NOD islet cells (Fig. 2F-J). These results indicate that the peritoneal exudate cells (rich in macrophages) but not $\mathrm{T}$ cells may induce the production of reactive oxygen intermediates in islet cells of the NOD and ILI mice. This production of reactive oxygen intermediates was partially blocked by SOD.

Experiment 2: peritoneal exudate cells from diabetic NOD females. Reactive oxygen intermediates were produced in islet cells from ILI females by peritoneal exudate cells from diabetic NOD females and the suppressive effect of SOD on the production of reactive oxygen intermediates is shown in Figure 3. The isletcells $\left(2 \times 10^{5}\right)$ were incubated with peritoneal exudate cells $\left(5 \times 10^{5}\right)$. The islet cells showed only $0.3 \%$ of fluorescein positive cells by themselves, $51.3 \%$ in the presence of peritoneal exudate cells, and $14.0 \%$ in the presence of peritoneal exudate cells and SOD (final concentration $13.4 \mathrm{U} / \mathrm{ml}$ ). The suppressive effect of SOD on the production of reactive oxygen intermediates in ILI islet cells by diabetic NOD females from assays in triplicate is shown in Figure 4. A doubled number of peritoneal exudate cells $\left(10 \times 10^{5}\right)$ slightly increased reactive oxygen intermediates in the islet cells. However, the production of reactive oxygen intermediates was suppressed by peritoneal exudate cells from SOD in both sets of samples.

Reactive oxygen intermediates were produced in islet cells from ILI females by macrophages but not T cells from diabetic NOD females (Fig.5). Macrophages but not $T$ cells from the diabetic NOD mice induced the production of reactive oxygen intermediates in the ILI islet cells. 

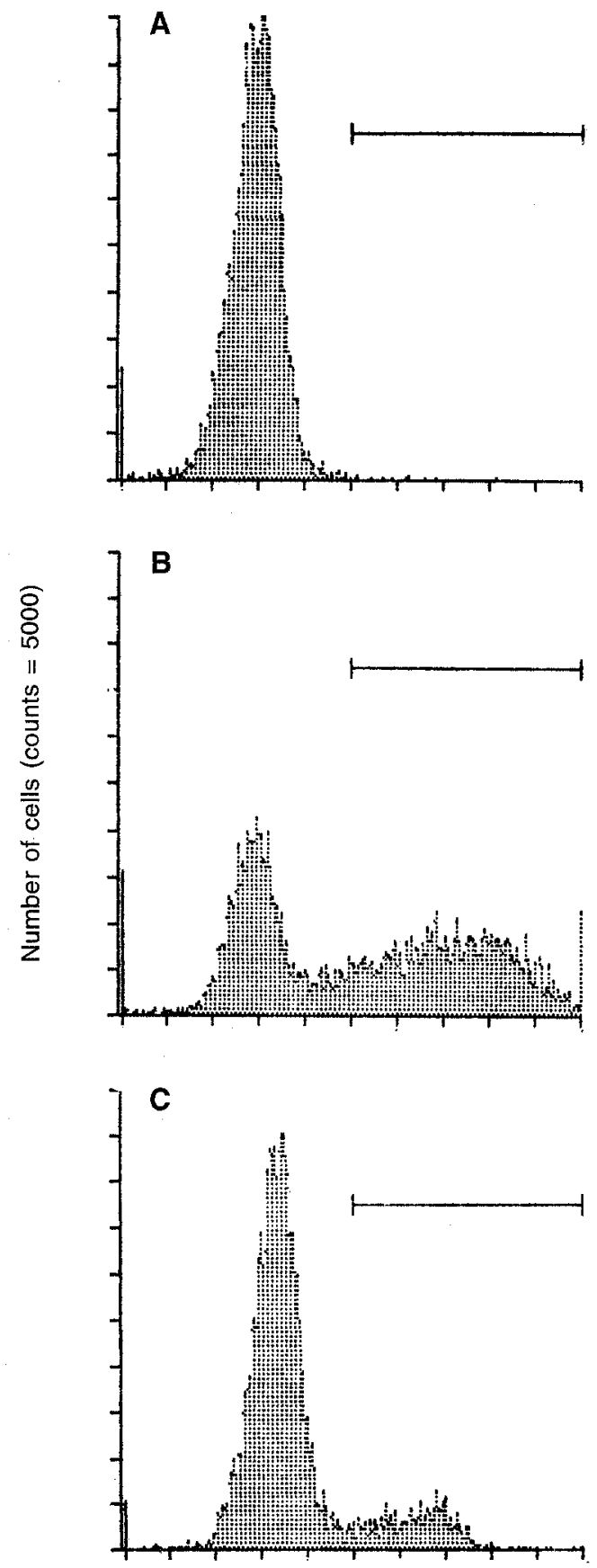

Log fluorescence intensity

Fig.3 A-C. Suppressive effect of superoxide dismutase (SOD) on reactive oxygen intermediate production by peritoneal exudate cells from diabetic NOD mice. Islet cells were prepared from ILI females and peritoneal exudate cells from diabetic NOD females. The islet cells and peritoneal exudate cells were co-cultured for $3 \mathrm{~h}$ prior to the addition of $2^{\prime}, 7^{\prime}$-dichlorofluorescein diacetate. Peritoneal exudate cells from diabetic NOD female mice induced the production of reactive oxygen intermediates even with the ILI islet cells. (A) Islet cells only. Reactive oxygen intermediates were produced in islet cells from ILI females by peritoneal exudate cells from diabetic NOD females (B) and suppressive effect of superoxide dismutase on the reactive oxygen intermediate production $(\mathbf{C})$

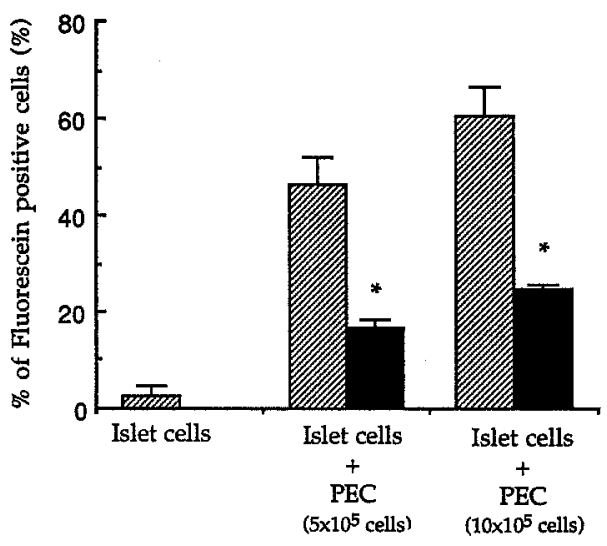

Fig.4. Suppressive effect of superoxide dismutase $(14.3 \mathrm{U} / \mathrm{ml})$ on reactive oxygen intermediate production in ILI islet cells by peritoneal exudate cells from diabetic NOD females. Peritoneal exudate cells (PEC) were tested at $5 \times 10^{5}$ and $10 \times 10^{5}$ cells with $2 \times 10^{5}$ islet cells. Values are expressed as mean \pm SEM from as-

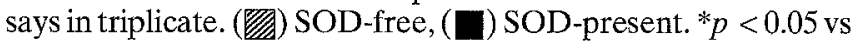
SOD-free

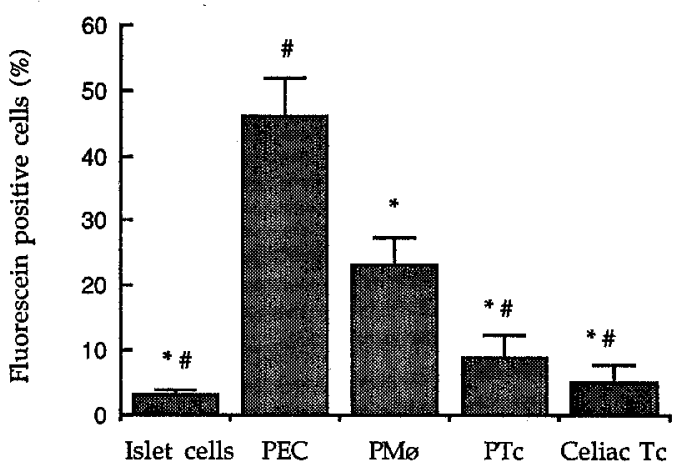

Fig.5. Reactive oxygen intermediate production in islet cells from ILI females induced by macrophages but not $T$ cells from diabetic NOD females. Islet cells from ILI females $\left(2 \times 10^{5}\right.$ cells $)$ were cultured with peritoneal exudate cells (PEC, $4 \times 10^{5}$; macrophage purity: $60 \%$ ), peritoneal macrophages (PM $\phi, 4 \times 10^{5}$; macrophage purity: $75 \%$ ), peritoneal T cells (PTc, $4 \times 10^{5}$, T-cell purity: $97 \%$ ), or $\mathrm{T}$ cells from celiac lymph nodes (celiac Tc, $4 \times 10^{5}$, T-cell purity: $95 \%$ ) from diabetic NOD females. Macrophages but not $\mathrm{T}$ cells from diabetic NOD females could induce the production of reactive oxygen intermediates in islet cells from ILI females. The bars indicate means \pm SEM $(\%)$ from five experiments. ${ }^{*} p<0.05$ vs PEC, \# $p<0.05$ vs PM $\varnothing$

Experiment 3: Cellular oxidation of 2', 7'-dichlorofluorescein in islet cells by hydrogen peroxide (non-specific oxidation). Hydrogen peroxide at $50 \mu \mathrm{mol} / \mathrm{l}$ induced maximal fluorescence-positive islet cells $(70.2 \%)$. Hydrogen peroxide at more than $100 \mu \mathrm{mol} / \mathrm{l}$ killed islet cells. To test the specificity of the effects of peritoneal exudate cells from NOD and ILI mice, ILI islet cells were cultured with PEC from NOD or ILI mice. Peritoneal exudate cells from both NOD and ILI could induce reactive oxygen intermediates in the ILI islets. Peritoneal exudate cells from $\mathrm{C} 3 \mathrm{H} / \mathrm{He}$, however, could not induce a significant production of reactive oxygen intermediates in islet cells from ILI or $\mathrm{C} 3 \mathrm{H} / \mathrm{He}$ mice. 


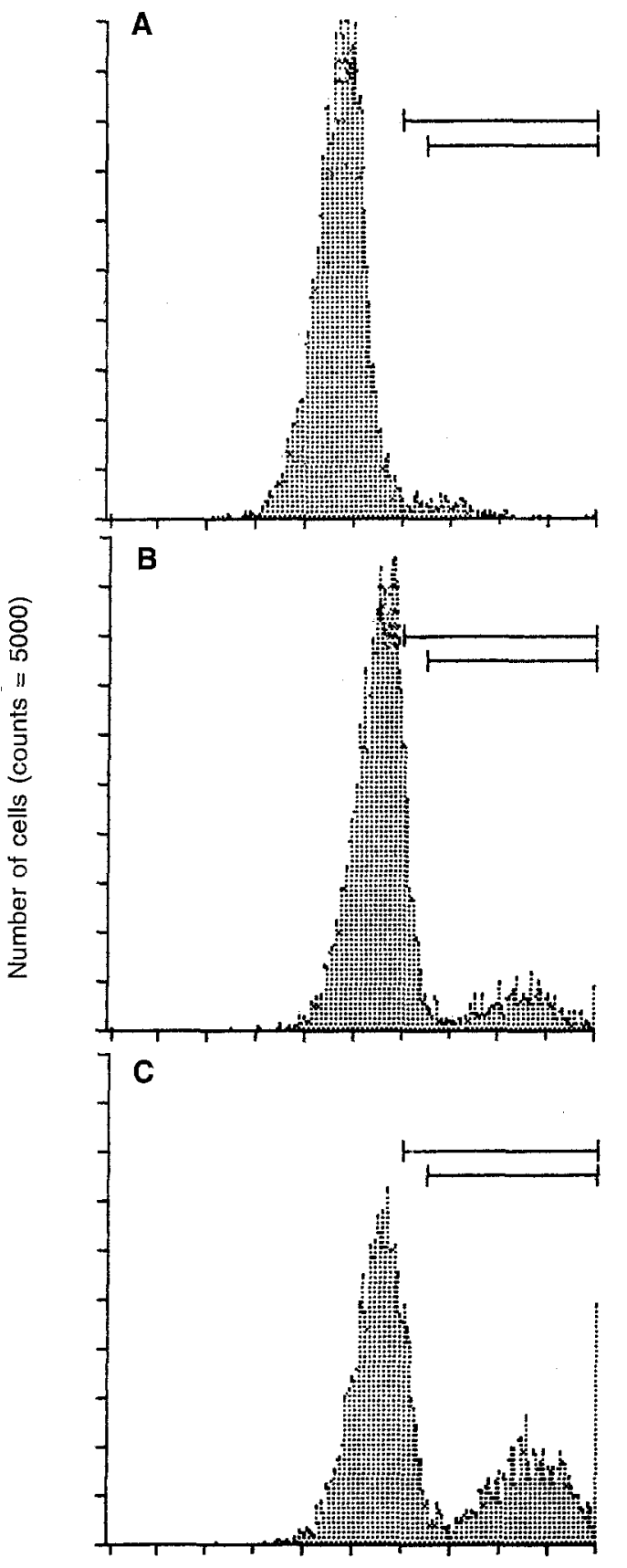

Log fluorescence intensity

Fig. 6. Reactive oxygen intermediate production in islet cells from ILI females induced by recombinant mouse interleukin-1$\alpha$. The islet cells were incubated with recombinant mouse interleukin-1- $\alpha\left(40 \mathrm{U} / 2 \times 10^{5}\right.$ islet cells $)$ for $3 \mathrm{~h}$ prior to the addition of $2^{\prime}, 7^{\prime}$-dichlorofluorescein diacetate. Percent of fluorescence-positive islet cells of the ILI mouse is shown in parentheses: $\mathbf{A}$ : islet cells alone $(4.2 \%)$; $\mathbf{B}$ : islet cells + interleukin-1- $\alpha(25.4 \%)$; : islet cells + PEC from diabetic NOD mice $(45.9 \%)$

Experiment 4: Reactive oxygen intermediate production by interleukin-1- $\alpha$. Recombinant mouse interleukin-1$\alpha$ could produce reactive oxygen intermediates in ILI islet cells (Fig. 6).

\section{Discussion}

Pre-treatment with a single intravenous injection of SOD-PEG protects mice against alloxan-induced hyperglycaemia [28]. The treatment with desferrioxamine (inhibitor of hydroxyl radical formation from superoxide anion), nicotinamide, or a combination of desferrioxamine and nicotinamide prevents disease recurrence in diabetic NOD mice after the allograft of $\mathrm{BALB} / \mathrm{c}$ islets [18]. Nomikos and co-workers [29] have recently reported that SOD and catalase are effective in preventing destruction of islet allografts of the $\mathrm{BALB} / \mathrm{c}$ mouse in diabetic NOD mice, as measured by continuing ability of the graft to regulate blood glucose.

In the present study, both SOD-PEG and catalasePEG were effective in preventing islet destruction of the NOD mice. The markedly increased absolute mass of undamaged islet portion observed in the treated groups may be due to the prevention of further betacell destruction by the action of SOD and catalase. Meanwhile, SOD and catalase from different species did not cause any allergic reactions, islet beta-cell tumours, or change in body weight in NOD mice. PEG attachment to purified enzymes has been shown to prolong the biological half-life of the enzymes [30]. Therefore, we used SOD-PEG and catalase-PEG instead of SOD or catalase alone. Although PEG itself can suppress immune reactions [31], a comparison of the data from the PEG-treated NOD mice with those from untreated NOD mice indicates that PEG alone had no protective effect on the islet in this study. The degree of islet damage in the untreated NOD females was similar to that in the PEG-treated NOD females at 3 months of age [32]. Therefore, the protection from islet-cell destruction observed in this study seems to be due to SOD and catalase themselves. During the present experiments with SOD-PEG, we had to evaluate its shortterm efficacy due to the high cost of SOD-PEG. A longterm (8 month) administration of SOD-PEG and catalase-PEG may be required to see whether the oxygen free radical scavengers coupled to PEG can prevent the development of diabetes in NOD mice.

Injection of splenocytes from diabetic NOD mice can transfer diabetes into irradiated young NOD mice [33]. Both $\mathrm{CD}^{+}{ }^{+}$and $\mathrm{CD} 8^{+}$splenic $\mathrm{T}$ cells are required for the adoptive transfer of diabetes in NOD mice [6]. Restricted usage of TcR in autoimmune diabetes has not been found in the NOD mouse $[8,9]$. However, T cells bearing TcR V $\beta 8$ are the major population in the islet-infiltrating cells of diabetic NOD mice, and that removing a major TcR V $\beta$ family $(\mathrm{V} \beta 8)$ appears to influence disease progression [5]. In this study, the treatment with either SOD-PEG or catalase-PEG did not change the proportion of $\mathrm{B}$ cells, $\mathrm{CD}^{+}, \mathrm{CD}^{+}$and $\mathrm{CD} 8^{+} \mathrm{T}$ cells, $\mathrm{T}$ cells bearing $\mathrm{TcR} \alpha \beta$ chains, nor $\mathrm{T}$ cells bearing TcR $V \beta 8.1,2,3$ in the spleen, as compared with those of the control group. Our data suggest that SODPEG and catalase-PEG do not exert the preventive ef- 
fect on islet beta-cell destruction by changing the number of $T$ cells. In our in vitro studies [34], peritoneal exudate cells (rich in macrophages) or T-cell depleted peritoneal exudate cells (macrophage-enriched fraction) could induce production of reactive-oxygen intermediates in the islet cells. However, nylon wool purified peritoneal $\mathrm{T}$ cells or $\mathrm{T}$ cells from celiac lymph nodes failed to induce production of reactive oxygen intermediates in the islet cells. The effect of peritoneal exudate cells (PEC) appears to be greater than the additive effects of peritoneal macrophages (PM $\varnothing)$ and $T$ cells (PTc) despite the increased number of macrophages in PM $\varnothing$ fraction. This observation indicates that macrophages may require interaction with $\mathrm{T}$ cells for maximal production of reactive oxygen intermediates in islet cells. Furthermore, the production of reactive oxygen intermediates in the islet cells by peritoneal exudate cells was inhibited by SOD-PEG (oxygen free radical scavenger). These observations suggest that SOD-PEG suppressed the production of reactive oxygen intermediates in the islet cells induced by macrophages, and thereby prevented the islet beta-cell destruction in the NOD mice.

Recent studies [35-37] suggest that macrophages play an important role in the initiation of insulitis in NOD mice. We speculate that the role of T cells and macrophages in the development of insulitis is as follows: Initially, an antigen(s) on islet beta cells may be processed by macrophages and presented to $\mathrm{CD} 4^{+}$helper T cells in an MHC class II restricted manner [38]. Indeed, the production of reactive oxygen intermediates in the islet cells by NOD peritoneal exudate cells appears to be MHC class II I-A-restricted [39]. Production of reactive oxygen intermediates in the islet cells was completely blocked by $\mathrm{mAb} 40 \mathrm{~A}$ reacting with NOD's MHC class II I-A [40], but not by mAb 14-4-4S reacting with MHC class II I-E, mAb 31-3-4S reacting with $\mathrm{MHC}$ class I $\mathrm{K}^{\mathrm{d}}$, or mAb 28-14-8S reacting with class $\mathrm{ID}^{\mathrm{b}}$. After the antigen presentation by the macrophages, the $\mathrm{CD} 4^{+}$helper $\mathrm{T}$ cells may be activated by the antigen-presenting cells and secrete lymphokines such as interferon- $\gamma(\mathrm{INF}-\gamma)$ resulting in activation of macrophages [41]. Activated macrophages may produce and secrete cytokines, such as interleukin-1 (IL-1) [42] and tumour necrosis factor [43], and simultaneously produce oxygen free radicals [11]. It was reported that IL-1 impaired the islet beta-cell activity in vitro $[44,45]$, and that IL-1, tumour necrosis factor and INF$\gamma$ have synergistically cytotoxic effects on islet cells in vitro [46]. In our flow cytometric analysis, recombinant murine IL-1 per se could induce production of reactive oxygen intermediates in the islet cells in vitro. Reactive oxygen intermediates produced either in the islet beta cells by interaction with the cytokines or directly by the activated macrophages could lead to beta-cell destruction.

The data in the present study suggest that in the prevention of islet beta-cell destruction of the NOD mouse SOD-PEG exerts its action/effect on peritoneal macrophages as effector cells rather than on $T$ cells as antigen recognizing and helper cells. It remains unclear whether the peritoneal macrophages must be stimulated by T-cell derived cytokines to produce reactive oxygen intermediates, or whether the peritoneal macrophages stimulate islet beta cells to produce reactive oxygen intermediates. The present study supports the concept that oxygen free radicals, such as superoxide anion and hydrogen peroxide, damage islet beta cells resulting in the development of diabetes.

Acknowledgements. We thank Dr. C.R. Kahn for his encouragement, Dr. J. W. Moorhead and Dr. R.T.Kubo for their constructive criticisms, and Mr. F.Bettinelli, Mr. D. DeLutis, Mr. K.J. Hirokawa and Dr. E. Yamato for technical assistance. This study was supported by grants from the Adler Foundation (M.H.), the Juvenile Diabetes Foundation International (M.H.), Procept, Inc., Shionogi \& Co., Ltd., NIH RO1 DK43613 (M.H.) and NIH 1P30 AM36836 (Diabetes and Endocrinology Research Center, Pilot and Feasibility Grant to M.H., Animal Core Facility and Tissue Culture Core). M.F. is the recipient of a Juvenile Diabetes Foundation Fellowship.

\section{References}

1. Gepts W (1965) Pathologic anatomy of the pancreas in juvenile diabetes mellitus. Diabetes 14: 619-633

2. Like AA, Rossini AA (1984) Spontaneous autoimmune diabetes mellitus in the BioBreeding/Worcester rat. Surv Synth Pathol Res 3: 131-138

3. Makino S, Kunimoto K, Muraoka Y, Katagiri K, Tochino Y (1980) Breeding of a non-obese, diabetic strain of mice. Exp Anim 29: 1-13

4. Makino S, Harada M, Kishimoto Y, Hayashi Y (1986) Absence of insulitis and overt diabetes in athymic nude mice with NOD genetic background. Exp Anim 35: 495-498

5. Fukuda M, Horio F, Kubo R, Hattori M (1989) Monoclonal antibody $\mathrm{F} 23.1$ against $\mathrm{T}$-cell bearing $\mathrm{V} \beta 8 \mathrm{TcR}$ elements can prevent the development of insulitis in NOD mice. Diabetes 38 [Suppl 2]: 12A (Abstract)

6. Miller BJ, Appel MC, O'Neil JJ, Wicker LS (1988) Both the $\mathrm{Lyt}-2^{+}$and $\mathrm{L} 3 \mathrm{~T}^{+}$subsets are required for the transfer of diabetes in non-obese diabetic mice. J Immunol 140: 52-58

7. Acha-Orbea H, Mitchell DJ, Timmermann L, Steinmann L (1988) Limited heterogeneity of T-cell receptors from lymphocytes mediating autoimmune encephalomyelitis allow specific immune intervention. Cell 54: 263-273

8. Shizuru JA, Taylor-Edwards C, Livingstone A, Fathmann CG (1991) Genetic dissection of $T$ cell receptor $V \beta$ gene requirements for spontaneous murine diabetes. J Exp Med 174: 633-638

9. McDuffie M (1991) Diabetes in NOD mice does not require T-lymphocytes expressing of $\mathrm{V} \beta 8$ or $\mathrm{V} \beta 5$. Diabetes 40 : 1555-1559

10. Uchigata Y, Yamamoto H, Kawamura A, Okamoto H (1982) Protection by superoxide dismutase, catalase, and poly (ADP-ribose) synthetase inhibitors against alloxan- and streptozotocin-induced islet DNA standard breaks and against the inhibition of proinsulin synthesis. $\mathrm{J}$ Biol Chem 257: $6084-6088$

11. Uchigata Y, Yamamoto H, Nagai H., Okamoto H (1983) Effect of poly (ADP-ribose) synthetase inhibitor administra- 
tion to rats before and after injection of alloxan and streptozotocin on islet proinsulin synthesis. Diabetes $32: 316-318$

12. Wilson GL, Leiter HE (1990) Streptozotocin interactions with pancreatic $\beta$ cells and the induction of insulin-dependent diabetes. Curr Top Microbiol Immunol 156: 27-54

13. Wilson GL, LeDoux SP (1993) Interactions of chemicals with pancreatic $\beta$-cells. In: Shafrir E (ed); Lessons from animal diabetes; Vol 4. Smith-Gordon, London, pp 17-26

14. Wilson GL, Hartig PC, Patton NJ, LeDoux SP (1988) Mechanisms of nitrosourea-induced $\beta$-cell damage: activation of poly (ADP-ribose) synthetase and cellular distribution. Diabetes 37: 213-216

15. Wilson GL, Patton NJ, McCord JM, Mullins DW, Mossman BT (1984) Mechanisms of streptozotocin- and alloxan-induced damage in rat B cells. Diabetologia 27: 587-591

16. Yamada K, Nonaka K, Hanafusa T, Miyazaki A, Toyoshima $\mathrm{H}$, Tarui S (1982) Preventive and therapeutic effects of largedose nicotinamide injections on diabetes associated with insulitis: an observation in non-obese diabetic (NOD) mice. Diabetes 31: 749-753

17. Murray HW, Spitalny GL, Nathan CF (1985) Activation of mouse peritoneal macrophages in vitro and in vivo by interferon. J Immunol 134: 1619-1622

18. Nomikos IN, Prowse SJ, Carotenute P, Lafferty KJ (1986) Combined treatment with nicotinamide and desferrioxamine prevents islet allograft destruction in NOD mice. Diabetes 35: $1302-1304$

19. Hattori M, Makino S (1988) Type I (insulin-dependent) diabetes. Exp Med 6: 78-86

20. Hattori M, Fukuda M, Ichikawa T, Baumgartl H-J, Kato H, Makino S (1990) A single recessive non-MHC diabetogenic gene determines the development of insulitis in the presence of an MHC-linked diabetogenic gene in NOD mice. J Autoimmunity $3: 1-10$

21. McCord JM, Fridovich I (1969) Superoxide dismutase. J Biol Chem 244: 6049-6055

22. Beers RF, Sizer IW (1952) A spectrophotometric method for measuring the breakdown of hydrogen peroxide by catalase. J Biol Chem 195: 133-140

23. Bonner-Weir S, Trent DF, Honey RN, Weir GC (1981) Responses of neonatal rat islets to streptozotocin: limited $\beta$-cell regeneration and hyperglycemia. Diabetes 30:64-69

24. Kubo TR, Born W, Kappler JW, Marrack P, Pigeon M (1989) Characterization of a monoclonal anitbody which detects all murine $\alpha \beta$ T-cell receptors. J Immunol 142: 2736-2742

25. Staertz UD, Rammensee H, Benedetto JD, Bevan MJ (1985) Characterization of a murine monoclonal antibody specific for an allotypic determinant on T cell antigen receptor. J Immunol 134: 3994-4000

26. Leo O, Foo M, Sach DH, Samelson LE, Bluestone JA (1987) Identification of a monoclonal antibody specific for a murine T3 polypeptide. Proc Natl Acad Sci USA 84: 1374-1378

27. Bass DA, Parce JW, Dechatelet LR, Szejda P, Seeds MC, Thomas M (1983) Flow cytometric studies of oxidative product formation by neutrophils: a graded response to membrane stimulation. J Immunol 130: 1910-1917

28. Grankvist K, Markland S, Taljedal I (1981) Superoxide dismutase is a prophylactic against alloxan diabetes. Nature 294: 158-160

29. Nomikos IN, Wang Y, Lafferty KJ (1989) Involvement of radicals in autoimmune diabetes. Immunol Cell Biol 67: 85-87
30. Abuchowski A, McCoy JR, Paiczuk NC, Van Es T, Davis FF (1977) Effect of covalent attachment of polyethylene glycol on immunogenecity and circulating life of bovine liver catalase. J Biol Chem 252: 3582-3586

31. Hershfield MS, Buckley RH, Greenberg ML et al. (1987) Treatment of adenosine deaminase deficiency with polyethylene glycol-modified adenosine deaminase. N Engl J Med 316: 589-596

32. Yano N, Ikegami H, Sato T et al. (1988) Orchiectomy increases L3T4 (helper) and Lyt2 (cytotoxic/suppressor) T lymphocytes in the thymus and accelerates B-cell destruction of the non-obese diabetic mouse. Diabetologia 31:560A (Abstract)

33. Wicker LS, Miller BJ, Mullen Y (1986) Transfer of autoimmune diabetes mellitus with splenocytes from non-obese diabetes (NOD) mice. Diabetes 35: 855-860

34. Fukuda M, Horio F, Rittershaus C, Kato H, Hattori M (1990) Macrophages but not T-cells can increase the content of freeradical oxygen in islet $\beta$-cells of the NOD mouse. Clin Res 38 : 308A (Abstract)

35. Charlton B, Bacelj A, Mandel TE (1988) Administration of silica particles or anti-Lyt 2 antibody prevents $\beta$-cell destruction in NOD mice given cyclophosphamide. Diabetes 37 : 930-935

36. Lee K, Amano K, Yoon J (1988) Evidence for initial involvement of macrophage in the development of insulitis in NOD mice. Diabetes 37: 989-991

37. Hutchings P, Rosen H, O'Reilly L, Simpson E, Gordon S, Cooke A (1990) Transfer of diabetes in mice prevented by blockade of adhesion-promoting receptor on macrophages. Nature 348: 639-642

38. Ziegler K, Unanue ER (1981) Identification of a macrophage antigen-processing event required for I-region-restricted antigen presentation to lymphocytes. J Immunol 127 : 1869-1875

39. Fukuda M, Horio F, Rittershaus C, Kato H, Hattori M (1991) MHC class-II I-A restriction of free-radical oxygen production in islet beta-cells by peritoneal exudate cells of the diabetic NOD mouse. Clin Res 39:246A (Abstract)

40. Ikegami H, Makino S, Harada M, Eisenbarth GS, Hattori M (1988) The cataract Shionogi mouse, a sister strain of the non-obese diabetic mouse: similar class II but different class I gene products. Diabetologia 31: 254-258

41. Adams D (1982) Molecules, membranes and macrophage activation. Immunol Today $3: 285-287$

42. Durum SK, Schmidt JA, Oppenheim JJ (1985) Interleukin-1: an immunological perspective. Ann Rev Immunol 3: 263-287

43. Beutler B, Greenwald D, Hulmes JD et al. (1985) Identity of tumor necrosis factor and macrophage-secreted factor cachectin. Nature 316: 552-554

44. Bendtzen K, Mandrup-Poulsen T, Nerup J, Nielsen JH, Dinarello CA, Svenson M (1986) Cytotoxicity of human pI 7 interleukin-1 for pancreatic islets of Langerhans. Science 232: 1545-1547

45. Palmer JP, Helqvist S, Spinas GA et al. (1989) Interaction of $\beta$-cell activity and IL-1 concentration and exposure time in isolated rat islets of Langerhans. Diabetes 28: 1211-1216

46. Pukel C, Baquerizo H, Rabinovitch A (1988) Destruction of rat islet cell monolayers by cytokines: synergistic interactions of interferon- $\gamma$, tumor necrosis factor, lymphotoxin, and interleukin 1. Diabetes 37:133-136 